\title{
CERVICAL SPINE IN PSORIASIS AND IN PSORIATIC ARTHRITIS*
}

\author{
BY \\ DAVID KAPLAN, CHARLES M. PLOTZ, LOUIS NATHANSON, \\ AND LAWRENCE FRANK \\ From the Downstate Medical Center, State University of New York
}

The radiological findings in psoriatic arthritis of the peripheral joints have been found to be similar to those in rheumatoid arthritis with two exceptions: the involvement of the distal interphalangeal joints in psoriatic arthritis, and the increased frequency of sacro-iliac changes in psoriatic as opposed to rheumatoid arthritis (Wright, 1961). Some authors would add a third difference, namely that the destructive lesion in psoriatic arthritis is more likely to lead to increased density of adjacent bone than to osteoporosis (Sherman, 1952).

While radiological studies have been reported for several of the various types of arthritis, no specific studies have been found describing the cervical spine in psoriatic arthritis. Lesions of the cervical spine in rheumatoid arthritis have been well described; they include destructive lesions of the occipito-atlanto-axial joints with subluxation (Martel, 1961), narrowing of the upper disk spaces, destructive changes of the apophyseal joints (Sharp, Purser, and Lawrence, 1958), and destructive lesions of the vertebral bodies (Seaman and Wells, 1961). The last finding is uncommon and may be related to steroid treatment. The characteristic findings in juvenile rheumatoid arthritis are very similar to those of ankylosing spondylitis (Ziff, Contreras, and McEwen, 1956). Narrowing and fusion of the apophyseal joints is a prominent feature and the lesions tend to involve the upper cervical joints, particularly $\mathrm{C} 2$ and 3 . The changes in the neck in ankylosing spondylitis, well described in the standard texts (Boland, 1960), consist essentially of ligamentous calcification and progressive haziness and narrowing of the apophyseal joints which may eventually lead to fusion.

In view of the many similarities of psoriatic arthritis to rheumatoid arthritis, and of the association of psoriasis and spondylitis noted above,

* Aided, in part, by a grant from the Arthritis and Rheumatism Foundation of New York. Work done under training grant 2A-5365(a), National Institutes of Arthritis and Metabolic Diseases, National Institutes of Health. $x$ rays of the cervical spine from patients with psoriasis and with psoriatic arthritis were compared with similar films from a control population. Evidence will be presented to suggest that the neck is indeed involved in both psoriasis and in psoriatic arthritis, and that the changes found bear a greater similarity to those described for spondylitis than they do to those associated with peripheral joint rheumatoid arthritis involving the neck.

\section{Material and Methods}

There were 52 patients in the group with psoriasis, of whom 34 had psoriasis alone and eighteen had a peripheral inflammatory or destructive polyarthritis with a negative latex-fixation test (Singer and Plotz, 1956) and were therefore considered to have psoriatic arthritis. There were 28 women and 24 men and the ages ranged from 18 to 74 years. While some of the older patients in this group undoubtedly had peripheral and cervical osteo-arthritis, it is believed that this fact does not influence the findings because of the nature of the control group selected-52 patients matched for age and sex.

The psoriatic patients were assembled from private practice and from the wards and arthritis clinic of a large municipal hospital. The control group included 41 patients in the same hospital whose necks were $x$ rayed for reasons other than rheumatoid arthritis or spondylitis, and eleven patients selected from an epidemiological survey carried out in New York City, whose necks were $x$-rayed because they had peripheral degenerative joint disease, with or without pain or disability in the neck.

In both groups the presence of a positive latex-fixation test and/or known ankylosing spondylitis, and in the control group of clinical rheumatoid arthritis, excluded the patient from the study.

Antero-posterior, lateral, open-mouth, and, in some instances, oblique $x$ rays of the cervical spine were taken of all patients in the study.

In the A-P view, the distance was 40 in., $100 \mathrm{MA}$ at $1 \mathrm{sec}$. and $52-56 \mathrm{kV}$, at a $5^{\circ}$ angle cephalad.

In the open-mouth view, the distance was 40 in., $100 \mathrm{MA}$ at $1 \mathrm{sec}$., and $52-56 \mathrm{kV}$, with no angle. 
Right and left obliques were taken at 40 in., 100 MA at $1 \mathrm{sec}$, and $54-58 \mathrm{kV}$, at a $10^{\circ}$ angle caudad.

Lateral views were taken at 72 in., $200 \mathrm{MA}$ at $3 / 20 \mathrm{sec}$., and $62-68 \mathrm{kV}$, with no angle.

The $x$ rays of the neck were evaluated and graded on previously-prepared forms in which the following information was recorded:

(1) Each apophyseal joint was examined for narrowing, erosions, and marginal sclerosis, and graded from 0 to $3 .^{*}$

* A score of $0=$ none; 1 = minimal or doubtful; 2 = moderate; 3 = severe or maximal (e.g. "severe" in the case of subluxation, "fusion" in the case of joint narrowing).
(2) Each intervertebral joint was examined for disk space narrowing, and graded from 0 to 3 .

(3) Each vertebral body was examined for osteoporosis, erosions, anterior and posterior proliferative changes, and subluxation, and graded from 0 to 3 .

(4) The presence or absence of paravertebral calcification was noted, as well as other relevant findings.

\section{Results and Discussion}

The results are tabulated for each patient in Table I, where each psoriatic subject is compared with a control matched for age and sex.

TABLE I

SUMMARY OF THE RADIOLOGICAL FINDINGS IN THE CERVICAL SPINES OF 52 PATIENTS WITH PSORIASIS AND 52 CONTROLS MATCHED FOR AGE AND SEX

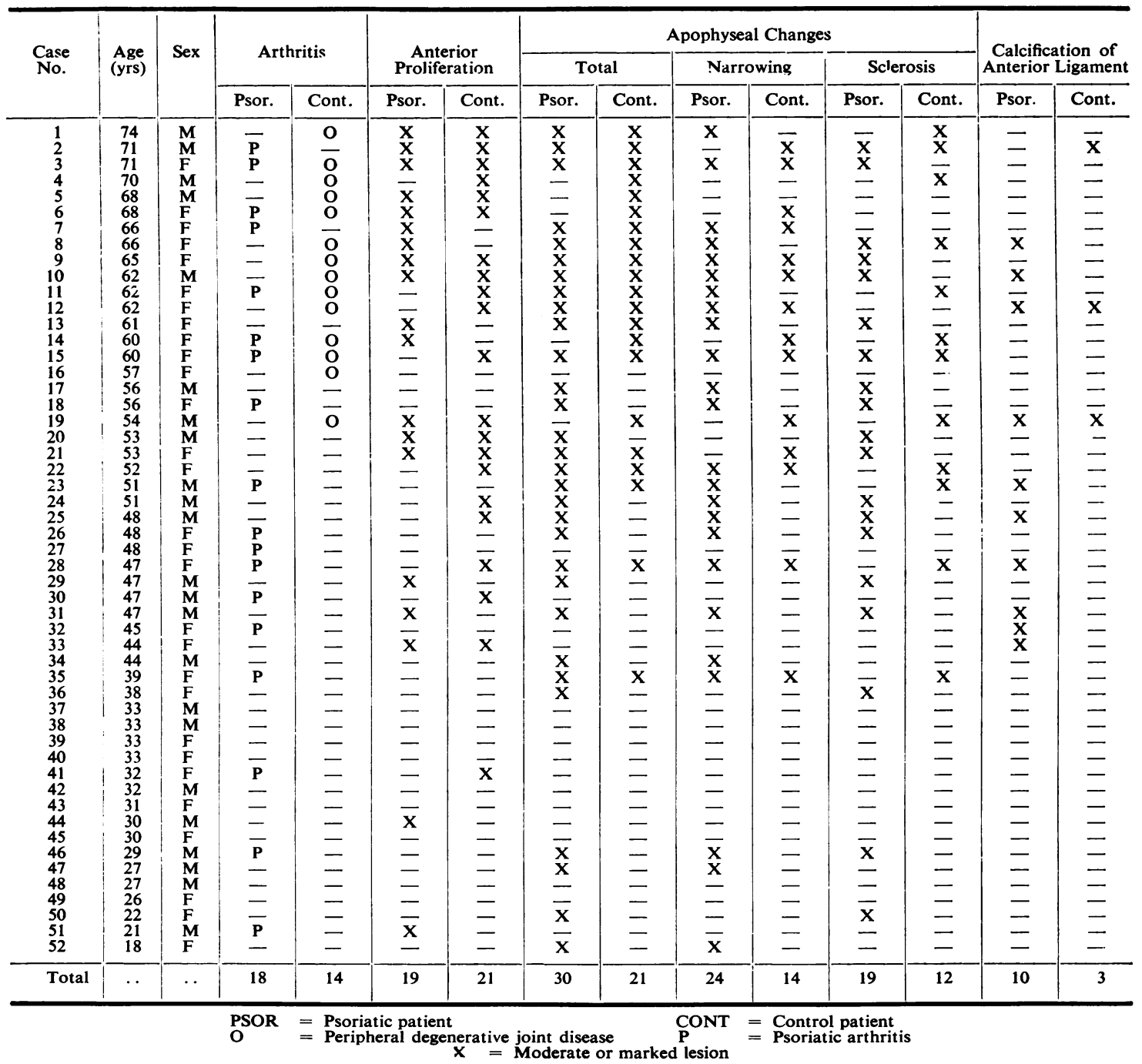


The data from Table I are summarized in Table II.

Anterior Proliferative Changes.-There is no real difference between the number of patients in each group demonstrating these changes of the cervical vertebrae; this indicates that the two groups are comparable with regard to the incidence of cervical osteo-arthritis which makes it improbable that the changes to be described as peculiar to psoriatic arthritis of the cervical spine are atypical or early osteo-arthritic changes.

Vertebral Osteoporosis and Vertebral Disk Space Narrowing.-Similar results are obtained for the relative incidence of these changes, both of which are seen in osteo-arthritis but also described in rheumatoid arthritis.

Apophyseal Joints.-The changes in these joints (narrowing, erosions, or sclerosis) are considerably more common in the psoriatic group. The difference becomes significant to $P<0.001$ if only patients under 60 years of age are included, presumably because the apophyseal changes which occur in degenerative joint disease in the older patients dilute the real difference between psoriatic and non-psoriatic subjects. The same is true for narrowing of one or more apophyseal joints, where only in patients under 60 years old does the intergroup difference become significant. Comparing the relative incidence of apophyseal changes of any type or merely apophyseal narrowing, when neither is accompanied by obvious evidence of degenerative disease (anterior proliferative changes), it is again clear that such changes are relatively common in the psoriatic patients and uncommon in the control subjects. Indeed, of the three control patients exhibiting apophyseal changes without anterior proliferative changes, one patient would be considered to have possible rheumatoid arthritis by the American Rheumatism Association criteria, and in the other two $x$-ray lesion is limited to one apophyseal joint only. This situation is in contradistinction to that in the psoriatic patients; of the sixteen psoriatic cases with joint narrowing, only four had the narrowing limited to one interspace.

If it were true that the cervical apophyseal changes are lesions characteristic of psoriatic arthritis, such lesions should be more common in patients with psoriatic arthritis than in patients with psoriasis alone. An analysis of the data bearing on this point is shown in Table III (opposite). While the differences in percentages do suggest that such a supposition may be correct, in no case are the differences large enough to be significant at the 5 per cent. level of confidence, and a larger group would have to be studied to determine whether the lesions described are primarily associated with psoriasis alone or with psoriatic arthritis. Certainly these lesions occur in the absence of clinical psoriatic arthritis.

Anterior Ligamentous Calcification.-This was present in ten of the psoriatic patients but in only

TABLE II

SUMMARY OF DATA PRESENTED IN TABLE I

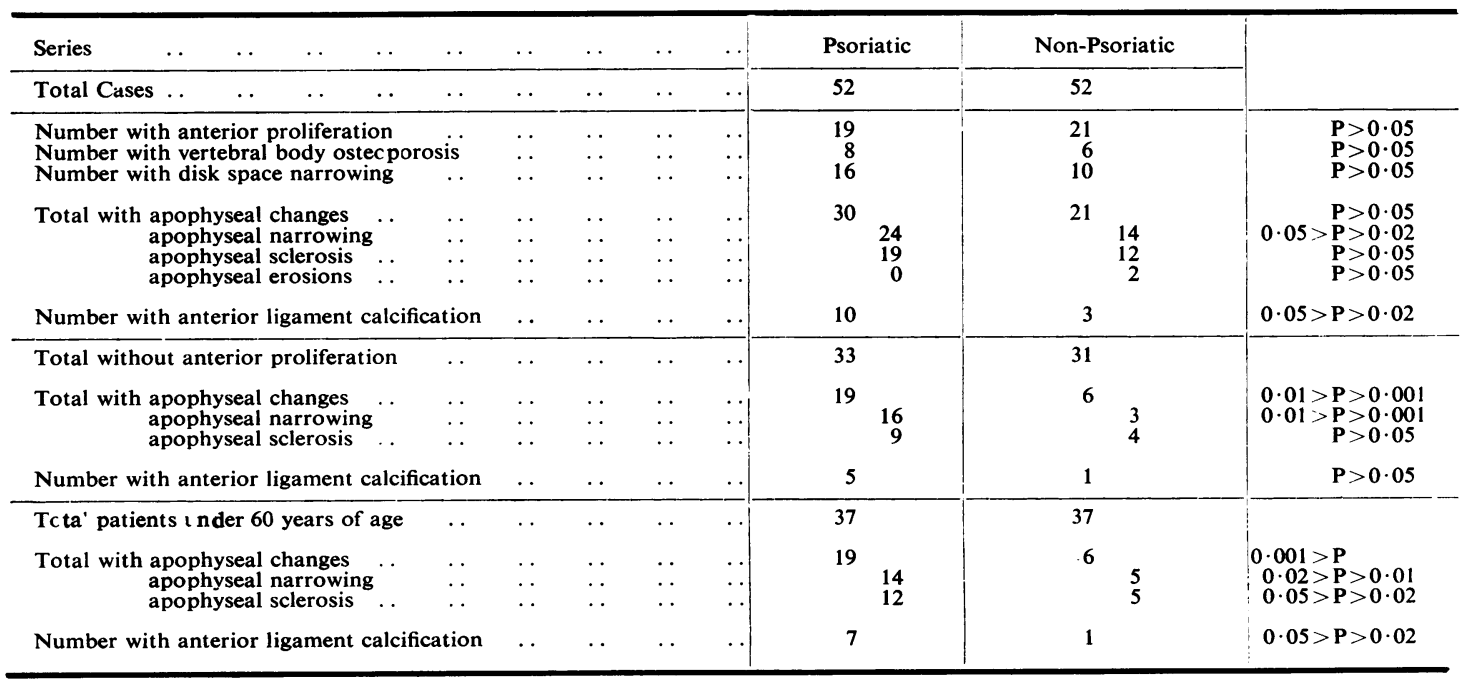


TABLE III

SUMMARY OF DATA FROM TABLE I COMPARING RADIOLOGICAL FINDINGS IN THE CERVICAL SPINE OF PATIENTS WITH PSORIATIC ARTHRITIS AND WITH PSORIASIS WITHOUT ARTHRITIS

(There is no significant difference between the two groups for any of the parameters tabulated here.)

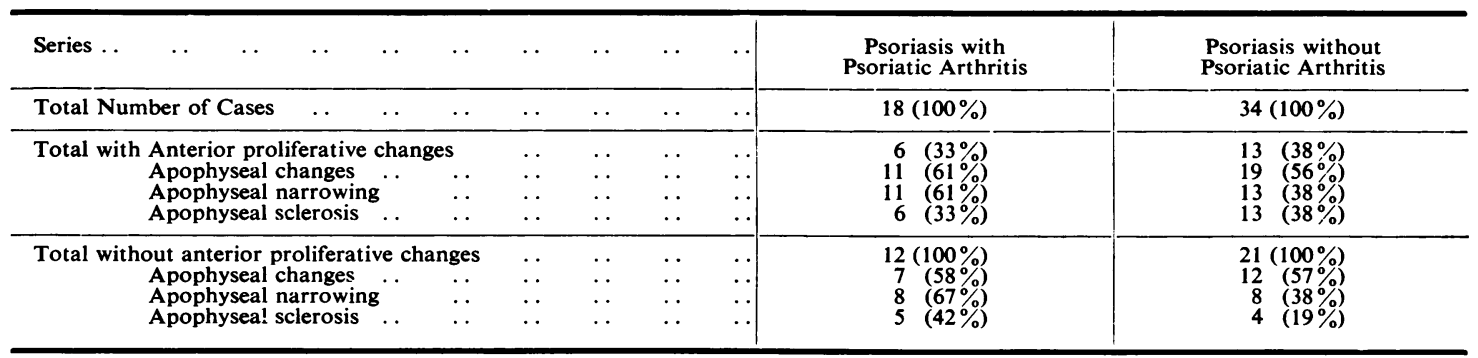

three of the control subjects $(0.02<\mathrm{P}<0.05)$; this, as well as the general similarity of the apophyseal changes described to those seen in ankylosing spondylitis, suggests that some of these cases may represent patients with spondylitis and psoriasis. However, there was no correlation between the

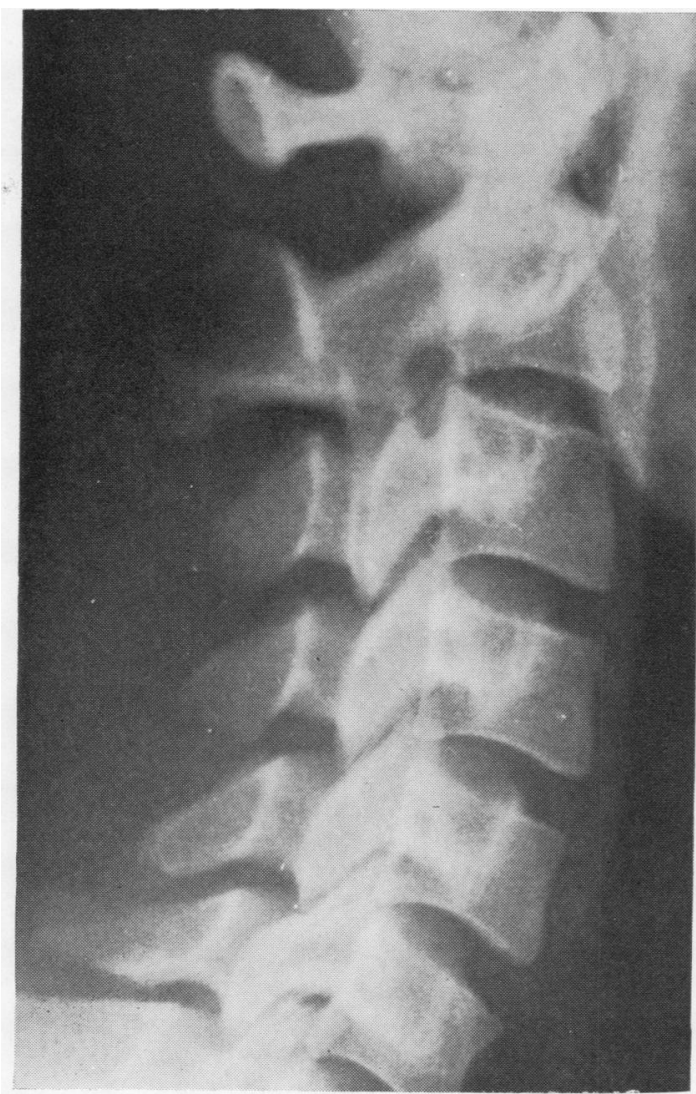

Fig. 1.-Normal cervical spine of a 27-year-old man. Note sharplydefined apophyseal joints with a good joint space and no marginal sclerosis. presence of ligamentous calcification and that of apophyseal changes in this very small number of patients and none of these patients had clinical evidence of involvement of the lower spine. No definitive answer can be given before a study has been made of the sacro-iliac areas and lumbar spines of this or a similar group of patients.

Erosions of the Subchondral Bone of the Posterior Articulating Facets.-These were not seen at all in the psoriatic group and seen in only two of the control group.

Fig. 1 shows a normal cervical spine and Fig. 2 advanced osteo-arthritis of the cervical spine.

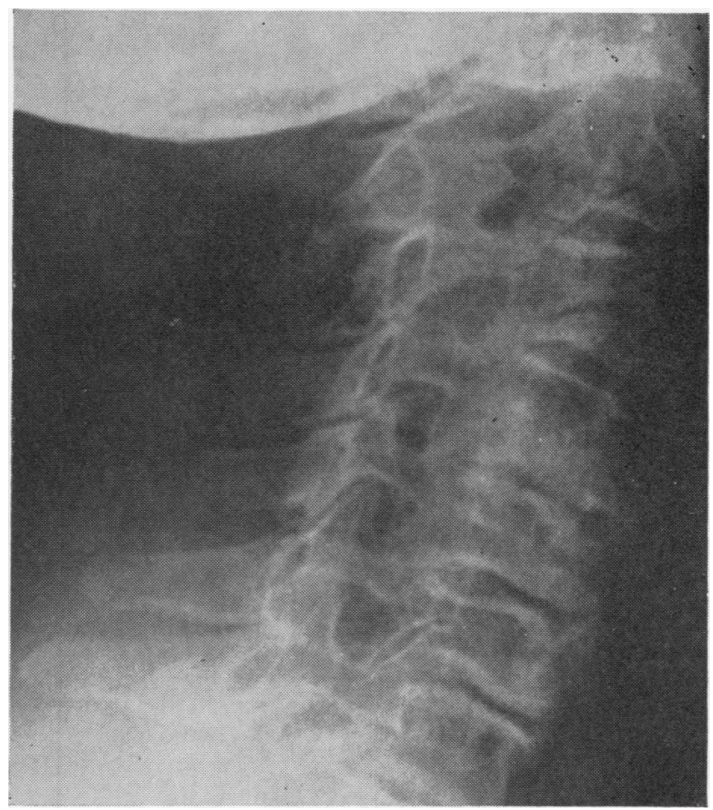

Fig. 2.--Cervical spine of a 68-year-old woman. The apophyseal joints between C5-6 and C6-7 are narrow and ill-defined, and demonstrate some osteoporosis. Note that these changes are minimal compared with those seen in the vertebrae and the disk spaces. 
Figs 3 to 6 show four examples of psoriatic changes of the cervical spine demonstrating the two characteristic lesions-narrowing and marginal sclerosis of the apophyseal joints. The frequency of the latter finding may be of particular interest in view of the suggestion, noted above, that, in peripheral joint disease, psoriatic patients demonstrate sclerosis of subchondral bone rather than osteoporosis. It cannot be stated that the sclerotic changes are secondary to cartilage destruction, as the sclerosis was frequently present in the absence of any demonstrable joint narrowing. This, of course, is also true for the osteo-arthritic cervical spines, and perhaps merely indicates the difficulty of evaluating the width of the joint space compared with the relative ease with which subchondral sclerosis can be demonstrated.

The rather high incidence of radiologically demonstrable involvement of the cervical spine in psoriatic arthritis reported here has been noted by other authors. Wright (1959) stated that seven of ten patients with psoriasis and "deforming arthritis"

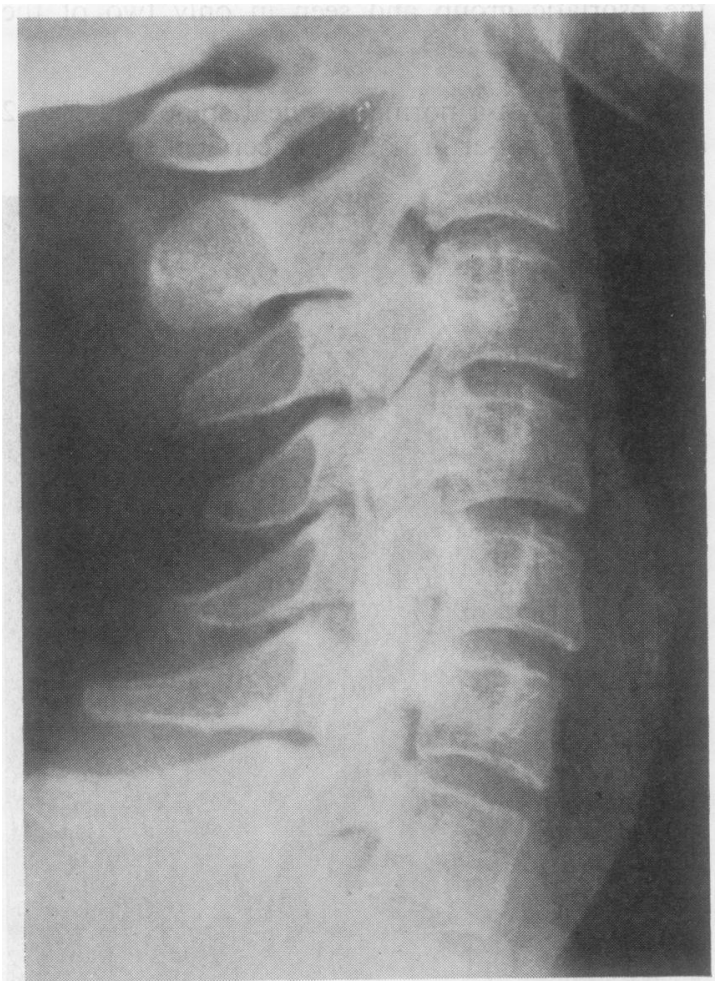

Fig. 3.-Cervical spine of a 29-year-old man with psoriasis and no peripheral joint disease. All the lower apophyseal joints exhibit narrowing and considerable marginal sclerosis in the absence of any significant anterior changes. not considered to be coincidental rheumatoid arthritis had neck involvement. His figures for a group of 118 patients with any variety of "rheumatic" complaint show an overall incidence of 25 per cent. with neck involvement.

The precise significance of these findings cannot be evaluated at present. Though previous descriptions of the cervical spine changes in rheumatoid arthritis would suggest that the changes seen in cases of psoriasis are not identical, a positive statement to this effect cannot be made before a study has been made of a control group matched for age and sex of patients with rheumatoid arthritis. The radiological appearances of these cervical lesions of psoriatic patients do, however, rather closely resemble those of the lesions considered characteristic of rheumatoid spondylitis. Joint narrowing and marginal sclerosis are common findings in both apophyseal joints and in the sacroiliac joints as, of course, is the presence of ligamentous calcification. Since these changes are the very ones seen in the psoriatic necks, the data here

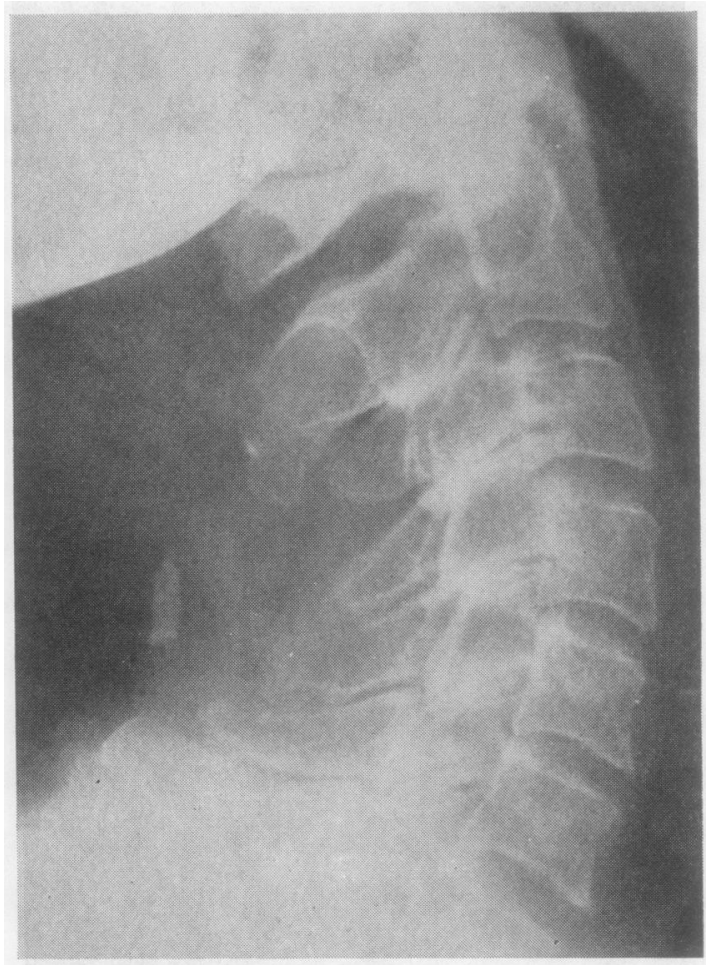

Fig. 4.-Cervical spine of a 56-year-old woman with psoriatic arthritis. Note narrowing and haziness of lower apophyseal joints and accompanying marginal sclerosis in the presence of only minimal anterior hypertrophic changes. 


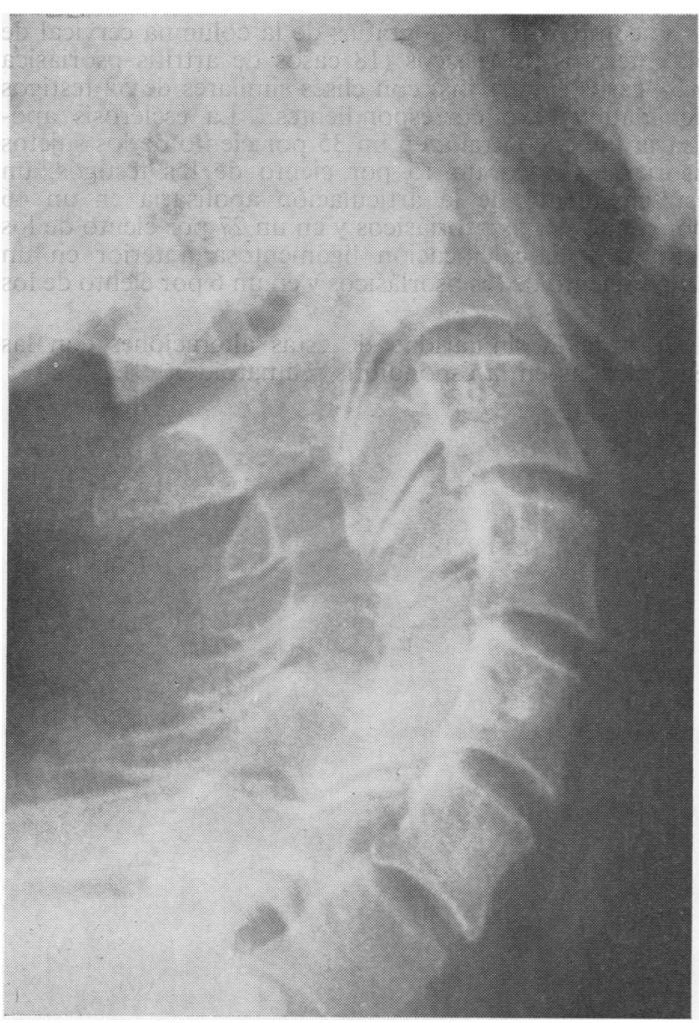

Fig. 5.-Cervical spine of a 44-year-old man with psoriasis but without peripheral arthritis. Note almost complete disappearance of apophyseal joint between C5-6.

reported lend support to the idea of Fletcher and Rose (1955) that there is an entity which might be called psoriatic spondylitis, analogous to the psoriatic arthritis of peripheral joints.

It is of interest to note that an uncontrolled $x$-ray study of the sacro-iliac joints and lumbar spine in fifty of the psoriatic patients showed no significant incidence of changes. This suggests that the cervical spine abnormalities are not part of a spondylitic syndrome.

\section{Summary}

Evidence is presented which suggests that a specific cervical lesion is associated with psoriasis and psoriatic arthritis.

$X$ rays of the cervical spine of 52 psoriatic patients (eighteen with psoriatic arthritis and 34 without arthritis) were compared with similar films of 52 control subjects matched for age and sex. Apophyseal sclerosis was found in 35 per cent. of the psoriatic subjects and 15 per cent. of the controls,

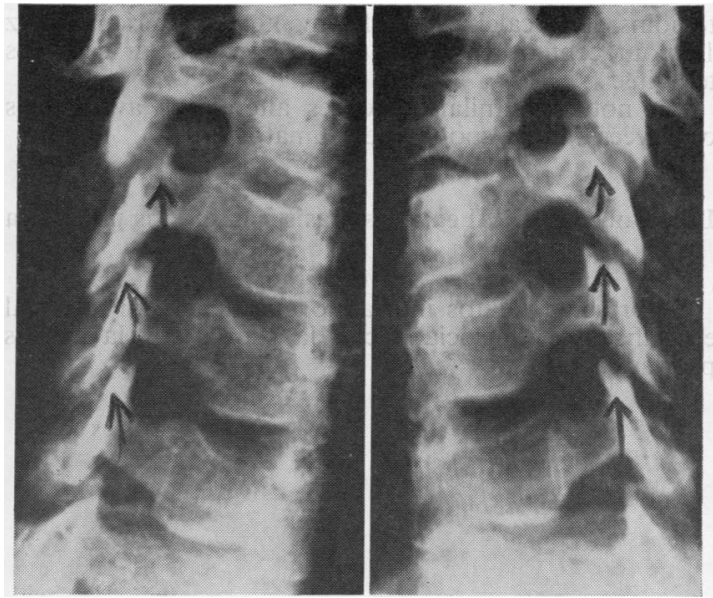

Fig. 6.-Oblique view of cervical spine of a 48-year-old woman with psoriatic arthritis. Note irregularity of apophyseal surfaces (arrows).

apophyseal joint narrowing in 46 per cent. of the psoriatics and 27 per cent. of the controls, and anterior ligamentous calcification in 19 per cent. of the psoriatics and 6 per cent. of the controls.

The similarity of these changes to those seen in rheumatoid spondylitis is noted.

\section{REFERENCES}

Boland, E. W. (1960). In "Arthritis", 6th ed., ed. J. L. Hollander. Lea and Febiger, London.

Fletcher, E. T. D., and Rose, F. (1955). Lancet, 1, 695. Martel, W. (1961). Amer.J. Roentgenol., 86, 223.

Seaman, W. B., and Wells, J. (1961). Ibid., 86, 241.

Sharp, J., Purser, D. W., and Lawrence, J. S. (1958). Ann. rheum. Dis., 17, 303.

Sheiman, M. S. (1952). J. Bone Jt Surg., 34A, 831.

Singer, J. M., and Plotz, C. M. (1956). Amer. J. Med., 21, 888.

Wright, V. (1959). Ibid., 27, 454.

(1961). Ann. rheum. Dis., 20, 123.

Ziff, M., Contreras, V., and McEwen, C. (1956). Ibid., $15,40$.

La colonne cervicale dans le psoriasis et dans l'arthrite psoriasique

\section{RÉSUMÉ}

On présente des faits indiquant qu'une lésion cervicale spécifique est associée au psoriasis et à l'arthrite psoriasique.

On a comparé des clichés radiologiques de la colonne cervicale de 52 malades psoriasiques (18 cas d'arthrite psoriasique et 34 cas sans arthrite) aux clichés similaires de 52 témoins d'âge et de sexe correspondants. Une sclérose apophysaire a été trouvée chez 35 pour cent des sujets psoriasiques et chez 15 pour cent des témoins, un rétrécissement de l'articulation apophysaire chez 46 pour cent des psoriasiques et chez 27 pour cent des 
témoins et la calcification ligamenteuse antérieure chez 19 pour cent des psoriasiques et chez 6 pour cent des témoins.

On note la similarité de ces altérations avec celles observées dans la spondylite rhumatoide.

La columna cervical en la psoriasis y la artritis psoriásica

\section{SUMARIO}

Se presentan datos indicando que una lesión cervical específica se ve asociada con la psoriasis y la artritis psoriásica.
Se compararon radiografías de la columna cervical de 52 enfermos psoriásicos (18 casos de artritis psoriásica y 34 casos sin artritis) con clisés similares de 52 testigos de edad y sexo correspondientes. La esclerosis apofisaria fué encontrada en un 35 por ciento de los sujetos psoriásicos y en un 15 por ciento de los testigos, un estrechamiento de la articulación apofisaria en un 46 por ciento de los psoriásicos y en un 27 por ciento de los testigos y la calcificación ligamentosa anterior en un 19 por ciento de los psoriásicos y en un 6 por ciento de los testigos.

Se nota la similaridad de estas alteraciones con las encontradas en la espondilitis reumatoide. 